\title{
Pós-graduação do Instituto Nacional de Pesquisas Espaciais numa perspectiva de gênero*
}

\author{
Maria Lígia Moreira** \\ Lea Velho***
}

\begin{abstract}
Resumo
Este trabalho tem como objetivo traçar um quadro da inserção das mulheres nos cursos de pós-graduação desenvolvidos pelo Instituto Nacional de Pesquisas Espaciais. Através de entrevistas com as egressas, são apresentadas as motivações que as levaram a escolher os cursos oferecidos e de que modo, segundo elas, estes contribuíram para as suas carreiras profissionais em uma área ainda considerada masculina - a área espacial.
\end{abstract}

Palavras-chave: Pós-Graduação, INPE, Mulheres.

\footnotetext{
* Recebido para publicação em abril de 2009, aceito em abril de 2010.

** Analista em Ciência e Tecnologia no Instituto Nacional de Pesquisas Espaciais, Doutora em Política Científica e Tecnológica da Universidade Estadual de Campinas.mligia@std.inpe.br

**** Professora titular em Estudos Sociais da Ciência e da Tecnologia junto ao Departamento de Política Científica e Tecnológica da Universidade Estadual de Campinas.velho@ige.unicamp.br
}

cadernos pagu (35), julho-dezembro de 2010:279-308. 
Pós-graduação do INPE numa perspectiva de gênero

Post-Graduate Education at the Brazilian National Institute for Space Research (INPE) from a Gender Perspective

\begin{abstract}
This paper aims to draw a picture of the involvement and participation of women in the post-graduate programs offered by the National Institute for Space Research (INPE) in Brazil. In doing so, it relies on quantitative data from various sources as well as on interviews with alumni in those courses. Interviews explore the motivations that led women to choose a research career in a field still considered typically male: space research.
\end{abstract}

Key Words: Graduate, INPE, Women. 
Maria Lígia Moreira e Léa Velho

\section{Introdução}

Ainda que as mulheres tenham participado ativamente na emergência, constituição, divulgação e institucionalização de diversas disciplinas científicas (Sedeño, 2000), foi nos últimos anos que houve expressivo crescimento do contingente das mulheres em atividades de ciência e tecnologia (C\&T), graças, em parte, aos movimentos feministas que estimularam a entrada delas nas universidades, nos centros de pesquisa e no mercado de trabalho (Leta et alii, 2006).

Apesar desse crescimento, os dados globais sobre a participação das mulheres em atividades científicas escondem áreas do conhecimento, instituições $e$ atividades em que tal aumento ainda não pode ser notado, ou é muito lento. Além disso, o crescimento na participação das mulheres nessas atividades não significa papéis iguais ou igualitários - os homens ainda estão nas posições mais altas e de poder de decisão.

$\mathrm{O}$ envolvimento das mulheres em atividades científicas no Brasil reflete, em linhas gerais, o panorama global. Apesar do crescimento da participação de mulheres, grande parte das disciplinas e áreas do conhecimento é dominada por homens, $e$ elas ainda são vistas como exceção, principalmente em algumas ciências exatas. Apesar das transformações pelas quais passaram algumas profissões, principalmente a partir da década de 70 , que abriram novas possibilidades para as mulheres que se formaram em carreiras nas quais os homens eram maioria, as opções feitas pelas mulheres ainda se concentram em algumas áreas específicas do conhecimento relacionadas principalmente à educação, à saúde e ao bem-estar social, humanidades e artes. Apesar do aumento no número de mulheres nas engenharias, construção $e$ produção na última década, ainda há dispersão em áreas como ciências, matemática e computação (MEC, 2008).

A concentração de mulheres em disciplinas científicas particulares e sua ausência em outras ainda não foi 
Pós-graduação do INPE numa perspectiva de gênero

suficientemente explicada, mas, em parte, é resultado de processos de socialização de homens e mulheres para papéis sexuais bastante distintos. Esse fenômeno, conhecido como gender tracking, tem se mostrado extremamente persistente $e$ refratário a mudanças, mesmo na presença de políticas destinadas a enfrentá-lo (Mason \& Goulden, 2003). Por isso, estudiosos do tema têm apontado e reafirmado a importância de realizar estudos no nível micro que explorem as razões que levam algumas mulheres a buscar as profissões tipicamente "masculinas" $e$, assim, ajudem a entender "o mistério do lento progresso das mulheres nessas áreas" (Angiers, 2009:2).

À luz do exposto, este estudo analisa a inserção das mulheres nos cursos de Pós-Graduação stricto senso desenvolvidos pelo Instituto Nacional de Pesquisas Espaciais INPE, refletindo sobre sua motivação para a formação em áreas e disciplinas nas quais os homens estão em maior número -ciências exatas, da terra e engenharias - e sobre a contribuição dos cursos para suas carreiras profissionais.

$\mathrm{O}$ argumento desenvolvido é que características específicas dos cursos do Instituto colaboram para o crescimento da participação de mulheres ao longo dos anos, motivando-as para a formação e para o ingresso na área espacial. Conhecer o grau de participação das mulheres, suas motivações para buscarem os cursos, $e$ as percepções sobre o impacto dos cursos na sua vida profissional contribuirá para a elaboração de ações que estimulem a multiplicidade de abordagens na área espacial, enriquecendo o ambiente acadêmico e profissional da área, através da participação igualitária de homens e mulheres.

O estudo se inicia com a apresentação das explicações oferecidas na literatura especializada para a assimetria que se verifica entre a participação de homens e mulheres na ciência, assim como para a existência de áreas do conhecimento $e$ profissões consideradas "tipicamente masculinas" $e$ "tipicamente femininas". É apresentada e discutida uma amostra da participação das mulheres na ciência brasileira utilizando dados do 
ensino superior e dos grupos de pesquisa do $\mathrm{CNPq}$, entre outras instituições. Na sequência, é analisada a participação das mulheres nos cursos do INPE, a partir de dados obtidos da Plataforma Lates do CNPq e do Serviço de Pós-Graduação do Instituto, e das entrevistas estruturadas com ex-alunas e ex-alunos do INPE.

\section{Gênero e produção do conhecimento}

Partindo do entendimento de que a produção de C\&T seria independente do contexto social, político e econômico, foi considerado por muito tempo que os atores sociais não tinham qualquer influência no conteúdo ou na trajetória do conhecimento. A partir da década de 1940, as dimensões sociais e históricas passaram a ser reconhecidas no processo de construção do conhecimento, também o sujeito pretensamente neutro passou a ser considerado. Assim, a relevância do sujeito, o caráter situado do conhecimento e seus elos com o poder passaram a ser levados em conta e os estudos feministas de C\&T começaram a discutir esses e outros aspectos (Cabral, 2007).

$\mathrm{Na}$ década de 1980 foram criados nas universidades inclusive em algumas universidades brasileiras - centros de estudos sobre a mulher e estudos de gênero e feminismos (Narvaz e Koller, 2006). No entanto, mesmo que estudos sobre gênero $e$ ciências venham se consolidando como campo disciplinar desde aquela década, ainda hoje no Brasil esses estudos são dispersos, mostrando que há muito trabalho para ser feito, a começar por uma sistematização do que existe publicado (Lopes, 1998).

A distribuição dos gêneros nas disciplinas mostra claramente a diferenciação entre homens e mulheres na ciência. Esse fenômeno, segundo Keller (1988), é resultado de um tipo de educação que atribui papéis distintos a meninas e meninos e, em geral, influencia o desenvolvimento de características pessoais $e$ profissionais entendidas muito mais como "emocionais" e do que "científicas" para as meninas. No decorrer do processo de 
Pós-graduação do INPE numa perspectiva de gênero

socialização, meninos são vistos como naturalmente aptos para as disciplinas exatas, enquanto as meninas são estimuladas para as sociais. E mesmo quando ascendem às carreiras acadêmicas em áreas para as quais presumidamente seriam mais aptas, as mulheres enfrentam desafios para os quais muitas vezes não foram educadas ou estimuladas, como processos acadêmicos competitivos ou o compromisso de dedicação exclusiva ao trabalho científico (Velho, 2006).

Em geral, a ciência é vista como uma atividade "tipicamente masculina" (Hayashi et alii, 2007) e a imagem de cientista é associada aos homens $e$, apesar da presença das mulheres no mundo científico, os "grandes cientistas", aqueles que são percebidos como porta-vozes autorizados da ciência, como os prêmios Nobel, membros da Academia de Ciências, diretores de instituições prestigiosas ou de laboratórios de elite, são na maioria dos casos do sexo masculino (Löwy, 2000).

Sobre a diferenciação de papéis na ciência, Kirkup e Keller (1992) argumentam que essa questão é debatida não somente porque as mulheres na ciência têm sido historicamente invisíveis, mas também porque há interpenetração entre o que se chama de gênero e de ciência. A ciência moderna é constituída de um conjunto de exclusões, tais como sentimentos e subjetividades que são atribuídas ao comportamento feminino. Portanto, "aprender a ser cientista é aprender atributos que nossa cultura atribui ao masculino" (Kirkup e Keller, 1992:47).

Nas carreiras onde os homens são maioria como as engenharias, muitas vezes as mulheres enfrentam o paradoxo de serem visíveis como mulheres, mas invisíveis como profissionais. Ao mesmo tempo em que enfrentam pressões para não perder sua feminilidade e para não se comportarem como homens, é esperado das mulheres engenheiras que se adaptem e se tornem "um dos rapazes, parte do grupo que compõe o espaço masculino" (Faulkner, 2006:14).

Eisenhart e Finkel (1998), ao estudarem as trajetórias de homens e mulheres dedicados à ciência e engenharia nos Estados 
Unidos, afirmam que ainda que estas e aqueles comecem suas carreiras como cientistas igualmente preparados, as mulheres na academia tendem - não por escolha própria, mas por designação superior - a iniciar suas carreiras como instrutoras, professoras $e$ outras posições hierarquicamente inferiores. Em muitos casos, essa tendência inicial de ocupar posições de menor status continua durante toda a carreira.

Considerando essas limitantes para o desenvolvimento da carreira científica pelas mulheres, muitos autores buscam explicar como elas poderão ultrapassar o "teto de cristal" (Hayashi et alii, 2006). Etzkowitz (2007) argumenta que há um fosso entre os valores ideais da ciência e aqueles efetivamente praticados, na medida em que as práticas sociais discriminatórias na ciência são levadas a cabo por cientistas que esperam que seu trabalho seja avaliado de acordo com critérios universalistas.

A ciência é cheia de desigualdades que invadem as carreiras profissionais e o espaço pessoal das mulheres. Se por um lado no século XIX algumas mulheres quebraram as barreiras e entraram nos laboratórios e na carreira acadêmica, a desigualdade de posições e oportunidades persiste, tornando difícil a determinação do provérbio "se o copo está meio cheio ou meio vazio" (Etzkowitz, 2007).

Ao longo desta pesquisa ficou evidente que os estudos sobre gênero e ciência têm um objetivo em comum, seja implícito ou explícito: refletir porque a participação das mulheres em C\&T é importante. Há uma diversidade de abordagens, entre as quais a que ressalta o dinamismo em certas áreas do conhecimento e daí importância da formação de equipes de pesquisa interdisciplinares e com múltiplos pontos-de-vista, o que é estimulado em equipes compostas por homens e por mulheres (Medeiros, 2008; Etzkowitz, 2007). Outra abordagem ressalta a contribuição que mulheres com formação científica podem dar, seja no campo pessoal, acadêmico ou profissional, para a formação de novas gerações de cientistas, contribuindo, conseqüentemente, para a expansão das atividades de C\&T (Eisenhart e Finkel, 1998; Souza, 2001) e para a construção 
Pós-graduação do INPE numa perspectiva de gênero

de forma igualitária do sistema nacional de pesquisa (Melo e Lastres, 2006).

\section{Mulheres na produção da ciência brasileira}

A educação, entre outros aspectos mais amplos, pode ser vista simultaneamente como causa e efeito da mudança operada nos papéis femininos, mas também imprimiu uma decisiva direção ao ingresso de mulheres no mundo científico (Ferreira et alii, 2008).

Beltrão e Alves (2004) afirmam que a reversão do hiato de gênero na educação brasileira possivelmente tenha sido a maior conquista das mulheres brasileiras no século XX. Elas souberam aproveitar as oportunidades criadas pelas transformações estruturais e institucionais ocorridas no país, dentre as quais as mudanças ocorridas no sistema escolar que garantiu equivalência de todos os cursos de grau médio e abriu a possibilidade das mulheres que faziam magistério disputarem os vestibulares.

Uma inovação importante para o desenvolvimento da C\&T no país foi a estruturação da pós-graduação a partir da década de 1960 , onde as mulheres lograram aumentar significativamente sua participação. Na década de 1970 o número de mulheres matriculadas em cursos de doutorado no Brasil representava $20,5 \%$ do total e três décadas depois ultrapassa os $50 \%$ (Tabela 1).

Tabela 1

Distribuição das alunas em cursos de mestrado e doutorado 2000-2006

\begin{tabular}{|c|c|c|c|c|}
\hline \multirow{2}{*}{$\begin{array}{c}\text { Nivel de } \\
\text { treinamento }\end{array}$} & 2000 & 2002 & 2004 & 2006 \\
\cline { 2 - 5 } & $\%$ Mulheres & \% Mulheres & $\%$ Mulheres & \% Mulheres \\
\hline Doutorado & $49 \%$ & $52 \%$ & $53 \%$ & $54 \%$ \\
\hline Mestrado & $52 \%$ & $55 \%$ & $56 \%$ & $57 \%$ \\
\hline
\end{tabular}

Fonte: Diretório dos grupos de pesquisa, $\mathrm{CNPq}$. 
O aumento global da participação das mulheres na pósgraduação pode ser explicado, em parte, pelo aumento dos cursos, alunos e titulados em Ciências Humanas e Biológicas, onde elas se concentram. Entre 2000 e 2006 o número de cursos em Humanas aumentou $53 \%$ e em áreas Biológicas aumentou $43 \%$, enquanto que os de Exatas e da Terra aumentaram $33 \%$.

As mulheres com bolsas do CNPq que se titularam no doutorado entre 1996 e 2003 se concentraram principalmente nas áreas de lingüística, letras e artes (74\%), ciências biológicas (63\%); humanas (57\%); e saúde (57\%); enquanto os homens se dedicaram em maior proporção às engenharias, ciências exatas $e$ da terra e agrárias, confirmando a tendência da procura delas por cursos ou departamentos tradicionalmente tidos como femininos, enquanto os homens procuram por setores de maior prestígio social e econômico (Dias, 2001; Keller, 1988), exceção feita à área biológica que, nos últimos anos, teve uma grande ascensão (Carvalho, 2008). Somente nas ciências sociais aplicadas o número de homens e mulheres bolsistas ficou bem próximo.

Tabela 2

Número de ex-bolsistas do CNPq que se titularam no Doutorado 1996-2003, segundo a grande área e sexo

\begin{tabular}{|l|c|c|c|}
\hline \multicolumn{1}{|c|}{ Grande área } & $\begin{array}{c}\text { Numero de } \\
\text { Mulheres }\end{array}$ & $\begin{array}{c}\text { Número de } \\
\text { Homens }\end{array}$ & $\begin{array}{c}\% \\
\text { Mulheres }\end{array}$ \\
\hline Ciências Exatas e da Terra & 700 & 1.272 & $35 \%$ \\
Ciências Biológicas & 953 & 543 & $63 \%$ \\
Ciências Humanas & 817 & 589 & $57 \%$ \\
Engenharias & 415 & 931 & $30 \%$ \\
Ciências Agrárias & 510 & 751 & $40 \%$ \\
Ciências da Saúde & 675 & 500 & $57 \%$ \\
Ciências Sociais Aplicadas & 225 & 265 & $49 \%$ \\
Lingüística, Letras e Artes & 319 & 111 & $74 \%$ \\
Não informada & 16 & 16 & $50 \%$ \\
\hline Total de titulados & 4.630 & 4.978 & $48 \%$ \\
\hline
\end{tabular}

Fonte: $\mathrm{CNPq}$ 
Pós-graduação do INPE numa perspectiva de gênero

Como resultado da trajetória de formação, atualmente há mais mulheres atuando como docentes em Humanidades do que em Engenharias. Tanto em instituições privadas de ensino superior como nas públicas, as mulheres representam menos da metade dos docentes, e é clara sua concentração em algumas áreas do conhecimento (Tabela 3).

Tabela 3

Docentes em instituições de ensino superior segundo grande área e sexo

\begin{tabular}{|l|r|r|r|r|}
\hline \multicolumn{1}{|c|}{$\begin{array}{l}\text { Grande área de } \\
\text { docência }\end{array}$} & Mulheres & Homens & $\begin{array}{c}\text { Não } \\
\text { informado }\end{array}$ & $\begin{array}{c}\% \\
\text { Mulheres }\end{array}$ \\
\hline $\begin{array}{l}\text { Agricultura e } \\
\text { veterinária }\end{array}$ & 3.854 & 7.382 & 92 & $34 \%$ \\
\hline $\begin{array}{l}\text { Ciências, } \\
\text { matemática e } \\
\text { computação }\end{array}$ & 13.028 & 21.967 & 209 & $37 \%$ \\
\hline $\begin{array}{l}\text { Ciências Sociais, } \\
\text { negócios e direito }\end{array}$ & 33.205 & 51.886 & 202 & $39 \%$ \\
\hline Educação & 29.487 & 20.611 & 236 & $59 \%$ \\
\hline $\begin{array}{l}\text { Engenharia, } \\
\text { produção e } \\
\text { construção }\end{array}$ & 7.492 & 20.743 & 118 & $26 \%$ \\
\hline $\begin{array}{l}\text { Humanidades e } \\
\text { artes }\end{array}$ & 7.148 & 7.176 & 59 & $49 \%$ \\
\hline $\begin{array}{l}\text { Saúde e bem-estar } \\
\text { social }\end{array}$ & 31.578 & 25.700 & 403 & $55 \%$ \\
\hline Serviços & 4.987 & 4.827 & 7 & $51 \%$ \\
\hline
\end{tabular}

Fonte: MEC/INEP/Sinaes

Apesar do processo de socialização que atribui papéis sociais distintos, é reconhecido que os meios formais de acesso à formação científica são, em tese, iguais para homens e mulheres. Desse modo, seria possível afirmar que, uma vez dentro do sistema de C\&T, as oportunidades são iguais para ambos os 
sexos? As evidências disponíveis indicam que há um descompasso entre a participação das mulheres e a ocupação de cargos de maior prestígio e mesmo quando homens e mulheres estão na mesma carreira, há distinção entre suas trajetórias profissionais: enquanto muitos deles chegam ao final das carreiras em cargos de direção, muitas delas chegam com atividades de apoio $e$ assessoria.

Hayashi et alii (2006) observam que poucos rostos femininos são vistos nos mais altos cargos de poder e prestígio em $\mathrm{C} \& \mathrm{~T}$, fenômeno que tem sido referido como "teto de cristal", o que pode ser evidenciado quando se olha para a participação das mulheres em cargos de direção em universidades e institutos de pesquisa no Brasil. Em 2008, havia apenas uma mulher em cargo de reitoria entre todas as universidades federais. Em cargos de assessoria o número de mulheres é bem mais significativo. Uma vez que ocupar altos postos hierárquicos significa ter poder de decisão, a participação das mulheres em cargos que assessoram esses altos postos mostra que, embora estejam envolvidas nos assuntos estratégicos nessas instituições e de fato contribuam com a gestão e desenvolvimento de C\&T, o poder de decisão ainda é dos homens e as trajetórias profissionais de muitas mulheres ficam nos limites do "teto de cristal".

Entre as possíveis explicações para as causas da representação desproporcional de mulheres em C\&T, está a que atribui o problema a diferenças biológicas, cognitivas ou de socialização entre os dois sexos. Segundo Soares (2001), os argumentos mais comuns em favor dessa hipótese são que mulheres não possuem controle emocional para suportar as pressões freqüentes em cargos de comando, que mulheres não tomam decisões objetivas e são socialmente educadas para serem protegidas $e$, dessa forma, não adquirem a agressividade necessária para competir. Uma segunda perspectiva propõe que os padrões institucionais determinam as escolhas individuais, que, por sua vez, mantêm e reforçam ciclicamente esses mesmos padrões. Assim, a questão de mulheres em C\&T é o resultado de 
Pós-graduação do INPE numa perspectiva de gênero

estruturas institucionais inapropriadas e não da inaptidão feminina para as áreas de C\&T. Como um efeito cíclico, o reduzido número de mulheres em cargos de decisão continua imprimindo comportamentos e padrões masculinos na condução da ciência e, conseqüentemente, na implementação de políticas e medidas que estimulem uma maior participação feminina em C\&T.

\section{Participação das mulheres no INPE}

Criado em 1961, o INPE originou-se do Grupo de Organização da Comissão Nacional de Atividades Espaciais (GOCNAE) como principal órgão de execução civil para o desenvolvimento das pesquisas espaciais no Brasil. O Instituto tem 11 unidades, distribuídas nos Estados de Maranhão, Ceará, Rio Grande do Norte, Mato Grosso, Rio Grande do Sul, São Paulo e no Distrito Federal. A unidade principal está localizada em São José dos Campos (São Paulo), onde funciona o Serviço de PósGraduação.

Atualmente, as mulheres representam $26 \%$ do total de servidores nas carreiras de gestão, pesquisa e desenvolvimento. Atualmente, o cargo chefe de gabinete da Direção do Instituto, que associa funções de gestão estratégica e de planejamento técnico-científico, é ocupado por uma pesquisadora. Nas chefias das coordenações, laboratórios e centros ligados às atividades-fim do Instituto não há nenhuma mulher (ciência do sistema terrestre, laboratórios associados, ciências espaciais e atmosféricas, entre outros). Por outro lado, nas áreas de gestão, as mulheres ocupam $27 \%$ dos cargos de chefia (informação e documentação, gestão de pessoas, gestão de competências, assistência e benefícios, entre outras áreas), mostrando um ambiente tipicamente masculino, do ponto de vista das lideranças internas das atividades-fim.

$\mathrm{O}$ quadro de pesquisadores e tecnologistas do INPE é constituído por 502 profissionais, dos quais 19\% são mulheres. Destes 502 profissionais, $48 \%$ dos homens são doutores, enquanto $10 \%$ das mulheres são doutoras (Gráfico 1). 
Maria Lígia Moreira e Léa Velho

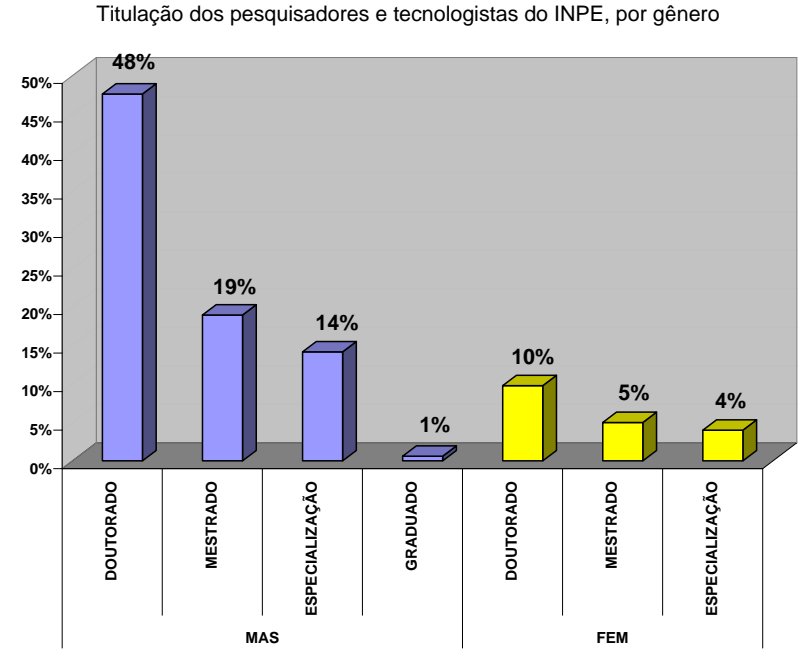

Gráfico 1 - Titulação dos pesquisadores e tecnologistas do INPE, por sexo.

\section{Mulheres na Pós-Graduação do INPE}

O Instituto, desde a sua criação, teve entre seus objetivos a formação de especialistas e, de modo a atender a esse objetivo, iniciou suas atividades de ensino através do núcleo de pósgraduação a partir do final da década de 1960.

Os primeiros programas do INPE, de natureza acadêmica e de pesquisa, eram voltados para a formação de pesquisadores para os projetos institucionais e de docentes que viriam a atuar nos próprios programas. Ao longo do tempo, alguns programas foram reestruturados e outros extintos, como os cursos de Engenharia de Sistemas e Tecnologias Educacionais.

$\mathrm{O}$ mestrado em Engenharia de Sistemas formou 114 mestres, entre os quais $19 \%$ eram mulheres. No curso de Tecnologias Educacionais, entre os pós-graduados $73 \%$ eram mulheres, confirmando a atração delas pela área da educação (Melo e Lastres, 2006). 
Pós-graduação do INPE numa perspectiva de gênero

O INPE oferece atualmente seis programas com cursos de mestrado e doutorado. Nestes cursos, até março de 2008 titularam-se 1540 mestres e doutores, dos quais $27 \%$ são mulheres.

Tabela 4

Número de titulados nos cursos de PG até 2007

\begin{tabular}{|l|r|r|r|r|}
\hline \multicolumn{1}{|c|}{ Programas } & Total & Homens & Mulheres & $\begin{array}{c}\% \\
\text { Mulheres }\end{array}$ \\
\hline Astrofísica & 70 & 55 & 15 & $21 \%$ \\
Mestrado & 37 & 29 & 8 & $22 \%$ \\
Doutorado & 108 & 84 & 24 & $22 \%$ \\
\hline Geofísica Espacial & 75 & 58 & 17 & $23 \%$ \\
Mestrado & & & & \\
Doutorado & 243 & 179 & 64 & $26 \%$ \\
\hline Computação Aplicada & 87 & 62 & 25 & $29 \%$ \\
Mestrado & & & & \\
Doutorado & 196 & 156 & 40 & $20 \%$ \\
\hline Engenharia e & 55 & 40 & 15 & $27 \%$ \\
Tecnologia Espacial & 196 & 127 & 69 & $35 \%$ \\
Mestrado & 55 & 34 & 21 & $38 \%$ \\
Doutorado & 389 & 280 & 109 & $28 \%$ \\
\hline Meteorologia & 29 & 20 & 9 & $31 \%$ \\
Mestrado & 1540 & 1124 & 416 & $27 \%$ \\
Doutorado & & & & \\
\hline Sensoriamento Remoto & & & & \\
Mestrado & & & & \\
Doutorado & & & & \\
\hline Total & & & & \\
\hline
\end{tabular}

Fonte: Serviço de Pós-Graduação do INPE

A presença das mulheres nos cursos do Instituto tem aumentado desde a criação dos programas (Gráficos 2 a 7). Nos cursos de mestrado e doutorado em computação aplicada atualmente a participação de homens é o dobro da participação de mulheres. Contudo, enquanto a participação de homens 
aumentou seis vezes desde a criação dos cursos (de 19 alunos nos anos 1970 para 112 entre 2000-2007), a participação de mulheres aumentou quase 28 vezes (de duas alunas nos anos 1970 para 54 entre 2000-2007). Mesmo assim, os homens ainda correspondem a $67 \%$ dos titulados em Computação, área que tem sido apontada como a mais masculina do sistema de C\&T brasileiro com apenas $25 \%$ de pesquisadoras (Cabral, 2006).

Dados do censo de 2000 mostram que 3.865 homens e 1.528 mulheres $-28 \%$ do total de titulados - concluíram mestrado ou doutorado em Computação naquele ano (IBGE, 2000). Das 41 bolsas concedidas pelo CNPq para formação e qualificação no exterior em 2008 na área de Computação, apenas seis (cerca de $15 \%$ ) foram para mulheres; das 1.184 bolsas no país, apenas 195 (16\%) foram concedidas a mulheres (CNPq, 2008). Além disso, o número de mulheres na graduação em Computação tem diminuído, tal como o da UNICAMP, que chegou a 2005 com apenas 5 alunas em uma turma de 50 (Schwartz et al, 2005).

Essa tendência à diminuição da presença de mulheres, entretanto, não se verificou no caso da pós-graduação em Computação no INPE. As entrevistas feitas com as egressas indicam que alguns aspectos dos cursos de computação do INPE a interdisciplinaridade e aplicação na área espacial - podem ser o fator de atração das mulheres. As dissertações e teses têm como objeto de estudo dados meteorológicos, sistemas para aeronaves, extração de atributos de imagens digitais, gerência de projetos, entre outros, aplicados a vários segmentos da área aeroespacial e as alunas vêm de diferentes áreas de graduação como Engenharia Cartográfica, Ciência da Computação, Administração de Empresas, Matemática, etc. De fato, como argumenta Etzkowitz (2007), o surgimento de novos campos interdisciplinares, nos quais as hierarquias ainda não estão bem estabelecidas, abre possibilidades para as mulheres enquanto profissionais. Uma entrevistada apontou que: 
Pós-graduação do INPE numa perspectiva de gênero

O doutorado em Computação Aplicada permitiu a integração de conhecimentos na área de computação muito importantes para o desenvolvimento da cartografia digital $e$ de SIG, e com isso, pude desenvolver minha pesquisa numa área de conhecimento na Cartografia, na época, recémestabelecida dentro da Associação Cartográfica Internacional, denominada de Visualização Cartográfica, o que caracteriza, sem dúvida alguma, pesquisa de ponta... (Silva, 2009).

A tendência de aumento da participação feminina ao longo dos anos também ocorreu nos cursos de Meteorologia, Engenharia e Tecnologia Espacial, Sensoriamento Remoto e Geofísica. Entre 2000 e 2007, no curso de Meteorologia houve maior proporção de mulheres em comparação aos demais cursos. Essa é uma área de pesquisa que cresceu muito nos últimos anos devido, principalmente, aos estudos de mudanças climáticas. No INPE, o curso é parte integrante das atividades do Centro de Previsão do Tempo e Estudos Climáticos (CPTEC) que combina atividades de pesquisa e desenvolvimento tecnológicos com atividades operacionais de previsão de tempo e clima, propiciando um ambiente de trabalho de formação acadêmica $e$ profissional. As respostas das egressas dos cursos de Meteorologia confirmam que a infra-estrutura oferecida pelos cursos $e$ a facilidade em aplicar os conhecimentos foram importantes na formação. As entrevistadas destacaram:

O nível dos Cursos de mestrado e doutorado que fiz no INPE foi excelente. O título deu um peso grande a minha vida profissional, pois concluir o Curso no INPE (mestrado $e$ doutorado) não era fácil! Também, nosso treinamento foi intensivo, amplo, voltado para a pesquisa, o que proporcionou uma visão mais global da Meteorologia. Com isso, tornei-me mais crítica cientificamente, mais exigente por pesquisa de qualidade, e tendo acesso a uma infraestrutura para pesquisa que poucas instituições têm 
disponível (biblioteca, dados, contatos internacionais e nacionais, etc.) (Souza, 2009).

[Eu] Trabalhava no desenvolvimento de aplicações científicas e poderia cursar a pós-graduação com enfoque nestas aplicações (Oliveira, 2009).

A variação no número de mulheres no programa de Sensoriamento Remoto foi de $22 \%$ na década de 1970 para $37 \%$ em 2000. As egressas apontaram como principal motivo da opção pela instituição a competência dos pesquisadores que atuam na pós-graduação e por ser um curso de excelência. ${ }^{1} \mathrm{~A}$ multidisplinaridade das linhas de pesquisa (agricultura, geologia, hidrosfera, ecossistemas, geoprocessamento, etc.) contribui para o ingresso de alunos graduados em diferentes áreas e disciplinas. A interdisciplinaridade do curso, segundo uma entrevistada fez com que houvesse moldado nela um perfil profissional extremamente híbrido e versátil. Para algumas entrevistadas, o curso de Sensoriamento Remoto do INPE contribuiu para uma formação sólida e o treinamento para a pesquisa. A importância do aprendizado da aplicação da tecnologia também foi destacada.

Nos cursos de Engenharia e Tecnologia Espacial a variação do número de mulheres foi grande - de zero na década de 1970 para $31 \%$ do total de alunos em 2000. Para uma entrevistada, graduada em Engenharia Industrial Química, a infra-estrutura e o ambiente de trabalho, com técnicos especializados e ótimos professores, foram fundamentais para a escolha da pós-graduação no INPE.

Por outro lado, nos curso de Astrofísica o número de homens entre 2000-2007 é três vezes maior do que quando o curso foi iniciado nos anos 1980, enquanto a participação das mulheres diminuiu. Nos anos 1980, o número de mulheres cursos de Astrofísica era de 50\% do total e em 2007 era de 20\%. A entrevista

${ }^{1}$ O conceito dos cursos na Capes é 6, na escala em que 7 é a nota máxima. 
Pós-graduação do INPE numa perspectiva de gênero

com as egressas apontou algumas dificuldades de inserção profissional reveladas já durante o curso. Segundo uma entrevistada, o reconhecimento internacional do curso abriu portas para ela no exterior, embora no decorrer do curso tenham sido poucas as possibilidades de aplicação dos conhecimentos adquiridos.

Os gráficos a seguir apresentam a variação da participação das mulheres ao longo dos anos, por programa.

\section{Gráfico 2}

Evolução do número de titulados em Computação Aplicada

por sexo

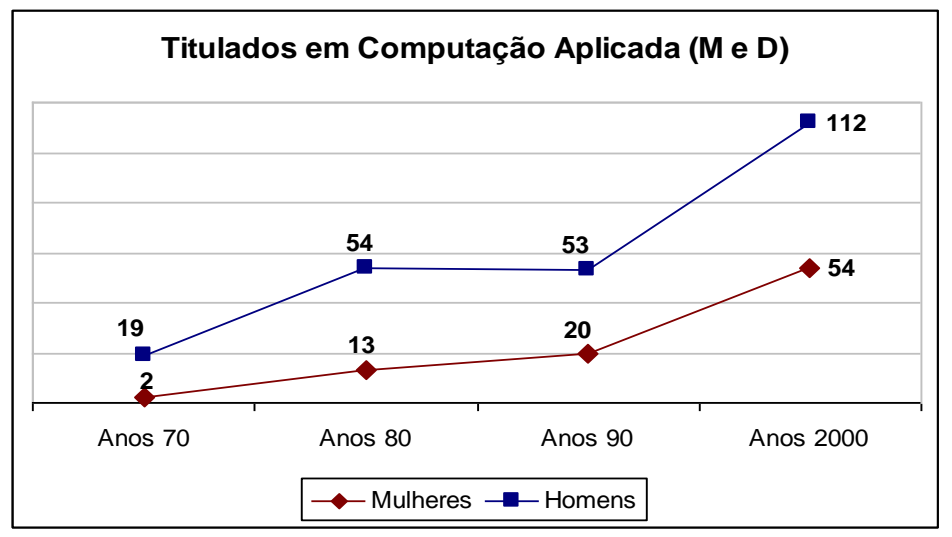


Gráfico 3

Evolução do número de titulados em Meteorologia por sexo

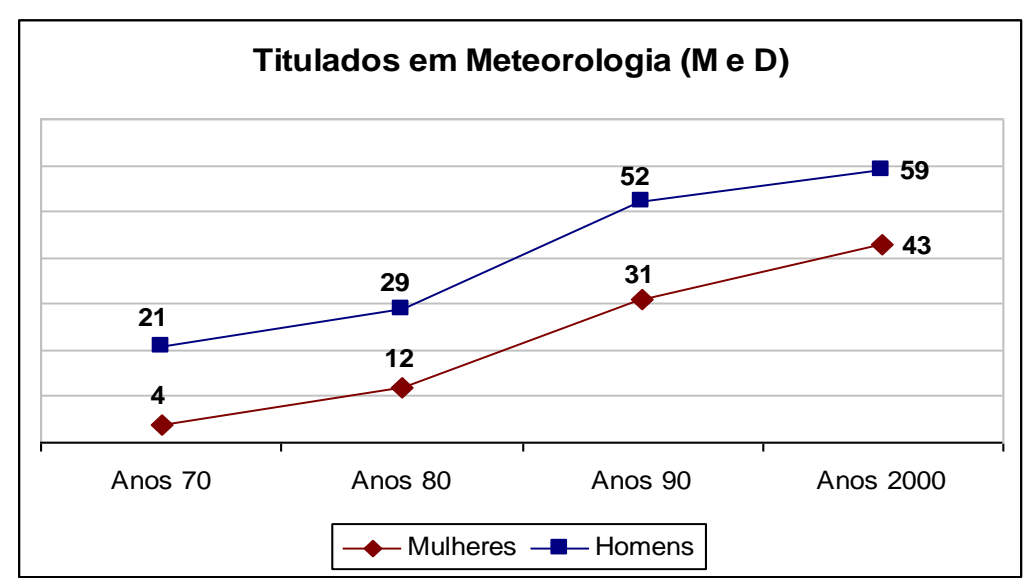

Gráfico 4

Evolução do número de titulados em Sensoriamento Remoto por sexo

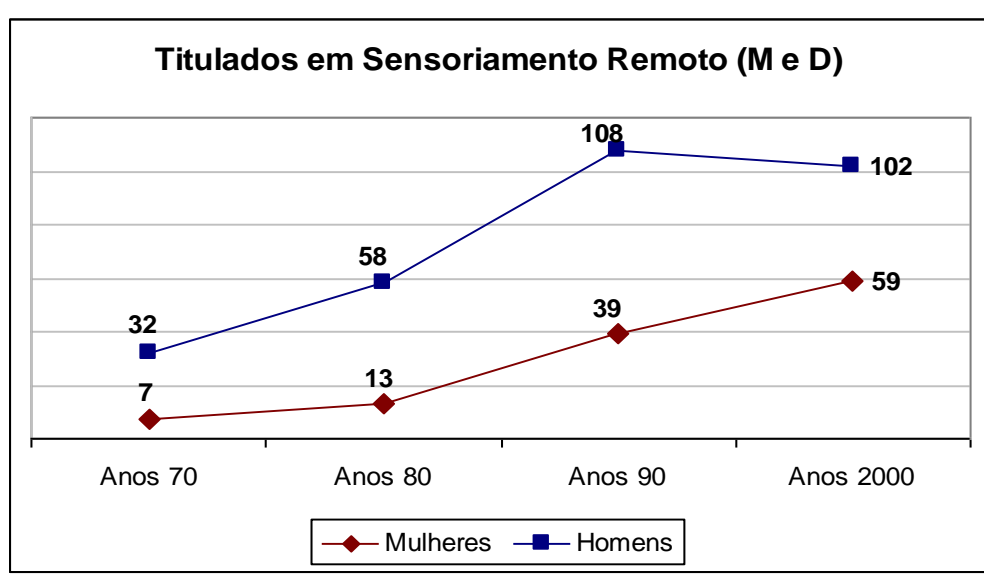


Pós-graduação do INPE numa perspectiva de gênero

Gráfico 5

Evolução do número de titulados em Astrofísica por sexo

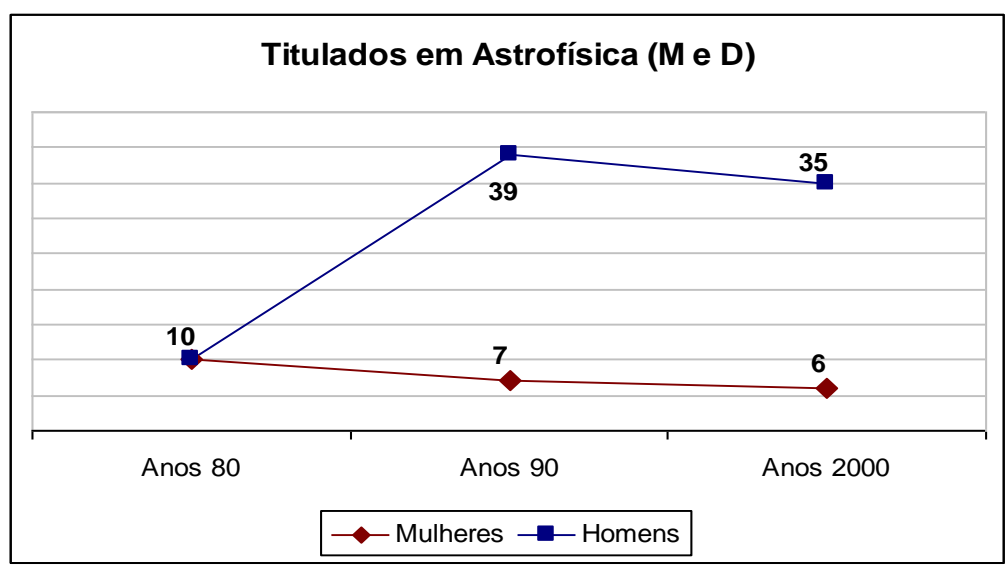

Gráfico 6

Evolução do número de titulados em Eng. e Tecn. Espacial por sexo

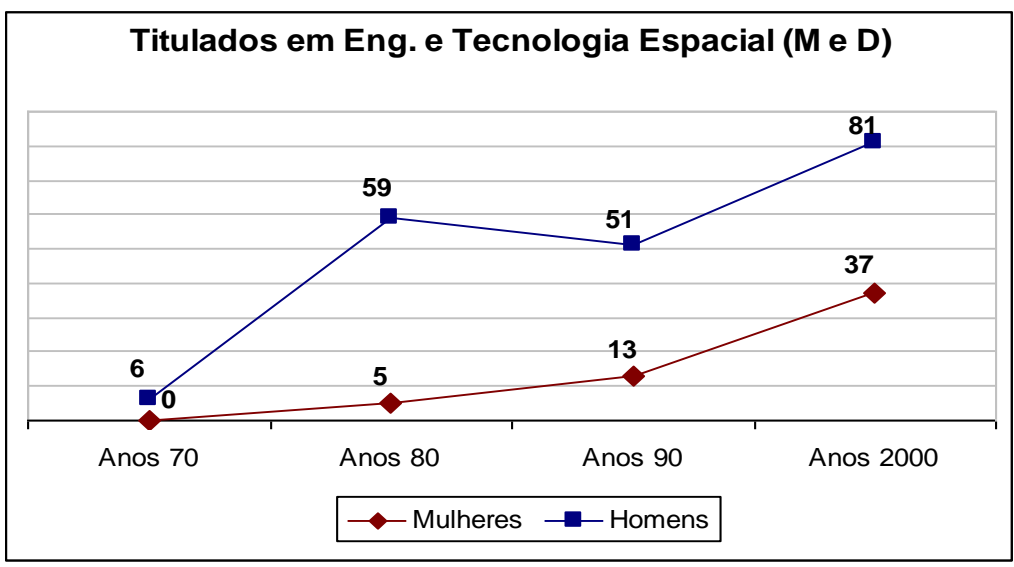


Gráfico 7

Evolução do número de titulados em Geofísica Espacial por sexo

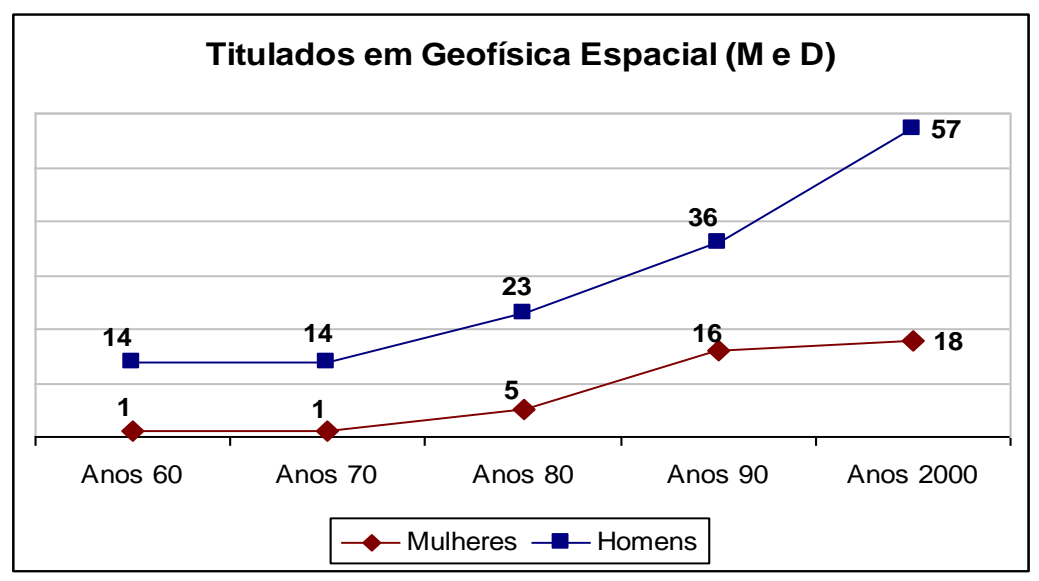

\section{As motivações e a importância da formação}

Ao falarem dos motivos que as levaram a optar pela pósgraduação do INPE, as mulheres destacaram o reconhecimento nacional $e$ internacional dos cursos, a infra-estrutura oferecida pelo Instituto, as linhas de pesquisa desenvolvidas, o alto nível dos docentes, a possibilidade de aplicação concreta do conhecimento.

O orientador do doutorado é um dos mais reconhecidos da área e contribuiu muito para minha formação (Ferreira, 2009).

(...) o INPE oferece uma infra-estrutura e um ambiente de trabalho inigualáveis, com técnicos especializados, ótimos professores e equipamentos de trabalho adequados às necessidades de aluno-pesquisador (Santos, 2009).

(...) a criação de um programa chamado Pró-Nuclear na Meteorologia do INPE. O curso de meteorologia permite 
Pós-graduação do INPE numa perspectiva de gênero

uma aplicação dos conceitos de física e eu queria fazer alguma coisa na Física que tivesse aplicação concreta (Souza, 2009).

Observa-se que no discurso das mulheres são apresentadas motivações totalmente racionais para a escolha dos programas do INPE, todas elas fundamentadas nas qualidades técnicas $e$ científicas. $\mathrm{Na}$ análise das entrevistadas sobre a contribuição dos cursos para suas carreiras foi destacada a importância de terem aprendido a executar atividades ligadas à pesquisa:

As atividades de pesquisa do INPE permitiram-me ampliar minha visão de ciência e tecnologia nos contextos prático e conceitual.

O mestrado abriu caminho para iniciar a pesquisa de computação aplicada (...) o curso mostrou a possibilidade de fazer atividades (...) de desenvolvimento associadas à investigação e contribuição para obter melhores respostas aos problemas científicos. Após a conclusão do mestrado, o potencial de pesquisa foi reconhecido e cogitada a possibilidade de ingressar na carreira de pesquisa. Hoje faço doutorado para concluir as exigências da carreira (Ramos, 2009).

Nenhuma das entrevistadas apontou explicitamente dificuldades ligadas às questões de gênero na escolha da área pósgraduação, mas algumas avaliam o ingresso nos cursos como uma "conquista". As entrevistadas falaram que as escolhas foram pautadas no que gostavam de estudar, na gratificação pessoal que cursar a pós-graduação traria, no interesse em ampliar os conhecimentos obtidos na graduação e da relevância da área de estudo:

Eu tinha muito interesse pela Astrofísica (Costa, 2009). 
Entendi que cursar uma pós-graduação poderia contribuir para meu aperfeiçoamento profissional e também minha gratificação pessoal (Gomes, 2009).

Sempre gostei das áreas de engenharia ligadas à energia, ao meio ambiente e à preservação ambiental, bem como as ligadas às atividades aeroespaciais. $\mathrm{Na}$ minha pósgraduação, pude aliar todas essas preferências num único curso (Silva, 2009).

A maioria das entrevistadas, com exceção de uma, apontou que de nenhuma forma observou-se discriminação por parte dos professores e estes não eram mais exigentes com as mulheres do que com seus colegas homens, nem era mais difícil para elas desenvolver o curso do que para eles. As egressas foram enfáticas ao afirmar que as mulheres não eram tratadas de forma diferente. As entrevistas não revelaram haver por parte das mulheres percepção de invisibilidade de atribuição a elas de papéis ou tarefas diferenciadas das dos homens. Nesse sentido, as egressas não tiveram problemas de integração no grupo, ainda que estivessem em menor número.

A diferença mais significativa entre as respostas das egressas e dos egressos foi o reconhecimento da importância em ingressar e concluir os cursos, o que evidenciou visões distintas. Os homens entrevistados, contrariamente às mulheres, não falaram de dificuldades provenientes do alto nível de exigência para o ingresso e para a conclusão dos cursos. Se, por um lado, as egressas ressaltaram como conquista o ingresso e a conclusão, valorizando o êxito na formação científica como resultado de esforço, os egressos enfatizaram principalmente a adequação dos cursos ao seu perfil acadêmico ou profissional.

A percepção diferente de homens e mulheres corrobora o que foi observado por Faulkner (2006) ao entrevistar grupos de homens e mulheres que optaram pela formação em engenharia. Para os entrevistados por Faulkner, não havia nada extraordinário no fato de homens optarem pela carreira de engenharia, ao 
Pós-graduação do INPE numa perspectiva de gênero

contrário de todas as mulheres entrevistadas que sempre tinham uma história para contar sobre como fizeram suas escolhas $e$ como enfrentaram os desafios, lembrando constantemente de que ser mulher e engenheira não era algo comum.

Apesar das mudanças nos padrões de acesso à formação educacional que tornaram possível maior acesso à formação acadêmica e a intensificação da presença feminina na comunidade científica brasileira, tanto na análise do que é produzido pela ciência quanto do seu processo e configuração, muitas mulheres ainda se vêem vencendo desafios ligados à questão de gênero.

\section{Considerações finais}

A análise da participação das mulheres na ciência brasileira evidencia o crescimento da formação acadêmica e da atuação profissional No entanto, são confirmadas algumas tendências gerais apontadas pela literatura: a concentração de mulheres em algumas áreas do conhecimento - elas ainda são minoria no trabalho como cientista e encontram dificuldade de ascender a cargos de maior prestígio tanto na academia como na pesquisa.

No caso dos cursos de pós-graduação do INPE, os números mostram que mesmo não havendo nenhuma política explícita de estímulo à participação de mulheres, esta tem crescido ao longo dos anos. Na década de 1970 foram 24 tituladas e entre 2000 e 2005 foram 217 tituladas. As influências decisivas, segundo as egressas, que as levaram a escolher cursos na área do Instituto foram: o reconhecimento nacional $e$ internacional, a infraestrutura, o corpo docente $e$ o ambiente de trabalho $e$, principalmente, o enfoque interdisciplinar em alguns deles.

O Espaço é objeto de estudos de diversas ciências. Assim, a maioria dos cursos admite graduados em diferentes áreas $e$ os trabalhos produzidos permitem abordagens a partir de múltiplas disciplinas. As entrevistadas apontaram a interdisciplinaridade como a característica que mais motivou as egressas a realizarem a 
PG no INPE. Os cursos interdisciplinares - Sensoriamento Remoto, Computação Aplicada e Meteorologia - são os que têm maior participação feminina.

Algumas das linhas de pesquisas desses cursos são modelagens de Tempo e Clima, Meteorologia Ambiental, Tecnologia da Informação e Extração da Informação, Sensoriamento Remoto aplicado à Agricultura e à Geologia, Geoprocessamento e Processamento de Imagens, nas quais a interdisciplinaridade colabora para a realização de trabalhos científicos relacionados aos múltiplos aspectos tratados pela ciência espacial.

Analisar a participação das mulheres em cursos de formação em uma área predominantemente desenvolvida por homens - a ciência espacial - se revelou não ser tarefa simples. $O$ fato de as entrevistadas não questionarem a adaptação ao modelo masculino da produção do conhecimento foi, a princípio, surpreendente, revelando que valores como a neutralidade, objetividade e racionalidade atribuídos à ciência e aos cientistas influenciam a percepção das mulheres sobre suas carreiras acadêmica e profissional. Essa concepção, segundo a qual C\&T são atividades autônomas $e$ independentes da sociedade e que seguem uma lógica própria, livre do contexto social, leva à adaptação a um modelo sem refletir sobre ele. Sem essa reflexão, não é desenvolvida a percepção de que a ciência tem lugar em contextos sócio-políticos determinados e, portanto, deve-se levar em conta sua íntima inserção e interação com a sociedade, a qual ela influencia e pela qual é influenciada (Santos e Ichikawa, 2006).

A participação das mulheres nos cursos do INPE, sem dúvida, tem contribuído efetivamente para o desenvolvimento da ciência espacial no Brasil. Analisar e prospectar o desenvolvimento da ciência espacial inclui considerar que processos de construção do conhecimento científico não estão isentos das assimetrias de gênero. Assim, será possível conhecer a contribuição das mulheres para o avanço da ciência espacial brasileira e estimular sua participação nessa área do 
Pós-graduação do INPE numa perspectiva de gênero

conhecimento. Além disso, como apontado por Soares (2001), o aumento da inserção de mulheres em C\&T pode contribuir para uma maior diversidade de abordagens e soluções para um dado problema, enriquecendo o ambiente acadêmico através de novos talentos, valores e motivações.

Como apontado Etzkowitz (2007) e Medeiros (2008), entre outros autores, o dinamismo em certas áreas do conhecimento acentua a importância da formação de equipes de pesquisa interdisciplinares e com múltiplos pontos-de-vista, o que é estimulado em equipes compostas por homens e por mulheres. A participação das mulheres na área espacial contribui não só para o avanço desse campo de conhecimento no presente como também para a formação de novas gerações e para novas perspectivas acerca da produção do conhecimento sobre o Espaço.

\section{Referências bibliográficas}

Aliaga-BuCHENAU, Ana-Isabel. A Educação da Sofia de Rousseau e da Lotte de Goethe: Pode o Romantismo Ser Reacionário? University of North Carolina at Chapel Hill, s/d. [Tradução de Lígia Maria Cardoso. UFSC, s/d.] [http://www.cfh.ufsc.br - acesso em 15/05/2008].

ANGIERS, Nathalie. "Geek Chic" and Obama, New Hope for Lifting Women in Science. New York Times, 19/Jan/2009 [http://www.nytimes.com - Acesso em 04/04/2009].

BeltrÃo, Kaizô Iwakami; AlveS, José Eustáquio Diniz. A reversão do hiato de gênero na educação brasileira no século XX. Trabalho apresentado no Encontro Nacional de Estudos Populacionais, Caxambu (MG), setembro de 2004.

BENSTON, Margaret Lowe. Women's voice/men's voices: technology as language. In: KELLER et alii. Inventing Woman. Polity Press, Cambridge, 1988, pp. 33-41.

CABRAL, Carla Giovana. Pelas telas, pela janela: o conhecimento dialogicamente situado. Cadernos Pagu (27), Campinas-SP, Núcleo de Estudos de Gênero - Pagu/Unicamp, jul-dez. 2006 [http://www.scielo.br - acesso em 12/03/2009]. 
CARVALHO, Eduardo. Um desafio à estrutura das revoluções científicas. Rev. Eletr. do Núcleo José Reis de Divulgação Científica, ano 9, $\mathrm{n}^{\circ}$ 36, 2008 [http://www.eca.usp.br - acesso em 21/04/2009].

CHAUí, Marilena. Convite à filosofia. São Paulo, Ática, 2005.

CNPq. Estatísticas. http://www.cnpq.br/estatisticas - acesso em 24/04/2008.

DiAS, A. L. M. As fundadoras do Instituto de Matemática e Física da Universidade da Bahia. História, Ciências, Saúde - Manguinhos, vol. VII(3), Rio de Janeiro, nov. 2000-fev. 2001, pp. 653-674.

EISENHART, Margaret. A.; FINKEL, Elizabeth et alii. Women's Science: learning and succeeding from the margins. United States, University of Chicago Press, 1998.

FAULKNER, Wendy. Genders in/of engineering: a research report. Science Studies Unit. Edinburgh, University of Edinburgh, 2006.

FERREIRA, Luís Otávio et alii. Institucionalização das ciências, sistema de gênero e produção científica no Brasil (1939-1969). História, Ciências, Saúde - Manguinhos, vol.15, supl., Rio de Janeiro, jun. 2008, pp.43-71.

GARCIA, Marta I.; SedeÑo, Eulalia Pérez. Ciencia, tecnología y género. Revista Iberoamericana de Ciencia, Tecnología, Sociedad e Innovación (2), 2002 [http://www.oei.es/revistactsi/ - Acesso em 30/04/2008].

GIFFIN, Karen. Produção do conhecimento em um mundo "problemático": contribuições de um feminismo dialético e relacional. Rev. Estudos Feministas, vol. 14, $\mathrm{n}^{\circ}$ 3, Florianópolis, 2006 [http://www.scielo.br - Acesso em 03/05/2008].

HAYASHI, M. C. et alii. Indicadores da participação feminina em Ciência e Tecnologia. TransInformação, 19(2), Campinas-SP, 2007, pp.169187.

IBGE. Censo Demográfico 2000 [ftp://ftp.ibge.gov.br].

Censos/Censo Demografico 2000/educacao/Brasil [Acesso em 20/05/2008]. 
Pós-graduação do INPE numa perspectiva de gênero

KAMOI, Maria de Lourdes; RiBEIRO, Frederico Fabbri. Relatório de Atividades de 1975. São José dos Campos, INPE, 1976.

Keller, Evely Fox. Gender and Science. Psychoanalysis and Contemporary Thought 1, 3, New York, International Universities Press, Inc. 1978.

How Gender Matters, or, why it's so hard for us to count past two. In: KELLER et alii. Inventing Woman. Polity Press, Cambridge, 1992, pp.42-80.

KELLER, Laurie. Discovering and doing: Science and Technology, an introduction. In: KeLLER et alii. Inventing Woman. Polity Press, Cambridge, 1988, pp.12-32.

LETA, Jacqueline; MARTINE, Carisey; SÉCHET, Patrick; OHAYON, Pierre. As mulheres na pesquisa, no desenvolvimento tecnológico e na inovação: uma comparação Brasil/França. Revista do Serviço Público 57 (4), Brasília, 2006, pp.531-548.

LOPES, Maria Margaret. Gênero e ciências no país: exceções à regra? Revista Comciência, 2003 [http://www.comciencia.br - Acesso em 23/04/2008].

. "Aventureiras" nas Ciências: Refletindo sobre Gênero e Historiadas Ciências Naturais no Brasil. Cadernos Pagu (10), Campinas-SP, Núcleo de Estudos de Gênero-Pagu/Unicamp, 1998, pp.345-368.

LöWY, Ilana. Universalidade da ciência e conhecimentos "situados". Cadernos Pagu (15), Campinas-SP, Núcleo de Estudos de GêneroPagu/Unicamp, 2000, pp.15-38.

MASON, Mary Ann e GOULDEN, Marc. Marriage and Baby Blues: Redefining Gender Equity. Trabalho apresentado na "Fast Track": Success of Parents in Demanding Professions Conference, University of Pennsylvania, 30 de Outubro de 2003 [http://ucfamilyedge.berkeley.edu/marriagebabyblues.pdf - Acesso em 24/03/2009].

MCT. Boletim Estatístico de Pessoal-2008. Disponível em http://www.servidor.gov.br/publicacao/boletim_estatistico/bol_estatisti co_08/Bol143_mar2008.pdf. Acesso em 25/06/2008. 
Maria Lígia Moreira e Léa Velho

MEC. Dados estatísticos [http://sinaes.inep.gov.br/sinaes - Acesso em 20/04/2008].

MEDEIROS, Cláudia. Mulheres em Computação: Uma questão estratégica, 2008 [https://www.sbc.org.br/horizontes/ edicoes/v01n01/pdfs/v01n01-22.pdf - Acesso em 14/03/2009].

MELO, Hildete Pereira; LASTRES, Helena Maria Martins. Mulher, ciência e tecnologia no Brasil. In: UNESCO. Proyecto Iberoamericano de Ciencia, Tecnología y Género (GENTEC): Reporte Iberoamericano. Madrid, OEI, 2004.

NARVAZ, Marta; KolleR, Silvia Helena. Metodologias feministas e Estudos de Gênero: articulando pesquisa, clínica e política. Psicologia em Estudo, vol. 11, n 3, Maringá, 2006, pp.647-654.

NogueIRA, Conceição. Feminismo e discurso do gênero na psicologia social. Psicologia e Sociedade, 13 (1), 2001, pp. 107-128.

OSADA, Neide Mayumi; CostA, Maria Conceição. Social construction of gender in biology: prejudice and barriers in molecular biology. Cadernos Pagu (27), Campinas-SP, Núcleo de Estudos de GêneroPagu/Unicamp, 2006, pp.279-299 [http://www.scielo.br - Acesso em 05/05/2008].

Red DE Indicadores De CiênCia y TeCnologia. Personal de CyT por gênero [http://www.ricyt.org/Indicadores/Comparativos/14.xls Acesso em 05/05/2008].

SCHWARTZ, Juliana et alii. Mulheres na informática: quais foram as pioneiras? Cadernos Pagu (27), Campinas-SP, Núcleo de Estudos de Gênero-Pagu/Unicamp, 2006 [http://www.scielo.br - Acesso em 11/12/2008].

SEDEÑO, Eulária Pérez. Institucionalización de la ciencia, valores epistémicos y contextuales: un caso ejemplar. Cadernos Pagu (15), Campinas-SP, Núcleo de Estudos de Gênero-Pagu/Unicamp, 2000, pp.77-102.

SILVA, Dilma. Mulheres em Computação. Revista Computação Brasil, vol. 21, Porto Alegre: 2006.

SOARES, Thereza Amélia. Mulheres em ciência e tecnologia: ascensão 
Pós-graduação do INPE numa perspectiva de gênero

limitada. Quím. Nova, vol. 24, n 2, São Paulo, abr. 2001 [http://www.scielo.br - Acesso em 13/03/2009].

THALER, Anita. Changes: Why women engineers change their career paths in technological research. University of Klagenfurt, 2007 [http://www.prometea.info/misc/documents/Thaler_Prometea-

Poster_Berlin\%202007.pdf - Acesso em 10/03/2009].

VelHo, Léa. Prefácio. In: SANTOS, L.W. et alii. Ciência, Tecnologia e Gênero: desvelando o feminino na construção do conhecimento. Londrina, IAPAR, 2006.

WAJCMAN, Judy. Domestic Technology: labour-saving or enslaving? In: KELLER et alii. Inventing Woman. Polity Press, Cambridge, 1988, pp.238-254.

WeBER, Leo. Desenvolvimento da Computação e da Arquitetura Computacional Assíncrona. Rev. Liberato (8), Nova Hamburgo, 2006, pp.1-16 [http://www.liberato.com.br - Acesso em 04/06/2008]. 